Acta Crystallographica Section D

Biological Crystallography

ISSN 0907-4449

\section{Crystallization and preliminary $X$-ray analysis of swine vesicular disease virus (SVDV)}

\author{
ISSN $0907-4449$
}

\section{Miguel A. Jimenez-Clavero, ${ }^{a}$ Victoria Ley, ${ }^{a}$ Ignacio Fita ${ }^{b}$ and Núria Verdaguer ${ }^{b} *$}

anstituto Nacional de Investigaciones Agrarias, Ctra. Coruña Km 7.5, 28040-Madrid, Spain, and

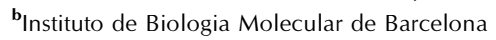
(CSIC), Jordi Girona 18-26, 08034-Barcelona, Spain

Correspondence e-mail: nvmcri@ibmb.csic.es
Three different crystal forms of the swine vesicular disease virus (SVDV), isolate SPA/2/'93, were obtained by the hanging-drop vapour-diffusion technique using ammonium sulfate and sodium/ potassium phosphate as precipitants. Monoclinic crystals, space group $C 2$, with unit-cell parameters $a=473.7, b=385.3, c=472.8 \AA$, $\beta=100.4^{\circ}$, contain one virus particle in the crystal asymmetric unit and diffract to $3.0 \AA$ resolution. A second type of crystals had a cubic morphology and diffracted beyond $2.6 \AA$ resolution. These crystals belong to a primitive orthorhombic space group, with unit-cell parameters $a=319.6, b=353.8, c=377.7 \AA$, and contain half a virus particle in the asymmetric unit. A third type of crystals, with a prismatic shape and belonging to space group I222, was also obtained under similar crystallization conditions. These latter crystals, with unit-cell parameters $a=318.3, b=349.9, c=371.7 \AA$, diffract to at least $3.0 \AA$ resolution and contain 15 protomers per asymmetric unit; this requires that three perpendicular crystal twofold axes coincide with three of the viral particles' dyad axes.
Received 1 October 2002 Accepted 23 December 2002

\section{Introduction}

Swine vesicular disease virus (SVDV), an enterovirus of the Picornaviridae family, produces a highly contagious disease that spreads rapidly by direct contact among infected animals and by environmental contamination. The similarity between the lesions caused by SVD with those produced by foot-and-mouth disease (FMD) has led to consideration of this disease as highly socially important and to the maintainance of routine surveillance for the presence of the virus in European countries (reviewed by EscribanoRomero et al., 2000). More than 100 SVDV isolates from Europe and Japan have been characterized by analysis of the nucleotide sequences of their capsid proteins and by determining their antigenic profiles. These isolates are classified into four different groups (Brocchi et al., 1997). Groups 1 and 2 are more closely related to each other than the more recent groups 3 and 4, which may represent two independent SVDV introductions into Europe from Asia, where SVDV strains have been isolated almost continually since 1970 (Zhang et al., 1999). The fourth group includes viruses isolated between 1987 and 1994 from Romania, the Netherlands, Italy and Spain. The different SVDV strains show a striking sequence homology to the human coxsackievirus B5 (CV-B5), with which they share 75-
$85 \%$ nucleotide sequence identity (Seechurn et al., 1990; Inoue et al., 1993; Zhang et al., 1993; Knowles \& McCauley, 1997). It has recently been demonstrated that SVDV is in fact a derivative of $\mathrm{CV}$-B5 and that this virus was introduced into pigs by interspecies transmission of CV-B5 from man between 1945 and 1965 (Zhang et al., 1999).

The SVDV virion consists of a nonenveloped capsid that encloses the viral genome, a single molecule of RNA(+) of 7400 nucleotides. The capsid, with the typical structural organization of picornaviruses, is formed of 60 protomers, each made up of one copy of each of the four structural proteins VP1, VP2, VP3 and VP4. The protomers selfassemble to form a $T=1$ icosahedron of 30 $32 \mathrm{~nm}$ diameter (Nardelli et al., 1968). In the mature virion of picornavirus, proteins VP1, VP2 and VP3 are exposed on the surface, forming a compact proteic shell. Conversely, VP4 is exposed at the inner side of the capsid, interacting with the viral RNA molecule. VP1, VP2 and VP3 are expected to present the tertiary structure that has been shown to be highly conserved among picornaviruses, consisting of a central hydrophobic core made up of an eight-stranded $\beta$-barrel. Loops joining the strands as well as the C-termini of the three polypeptides are exposed on the surface of the capsid, whereas their N-termini are located facing the interior.
(C) 2003 International Union of Crystallography Printed in Denmark - all rights reserved 
We report here the crystallization of SVDV in three different crystal forms that appear suitable for high-resolution structural studies. The arrangement of the viral particles within the different unit cells is also discussed.

\section{Experimental results}

\subsection{Purification}

SVDV was propagated in IB-RS-2 pig kidney cells (De Castro, 1964) as follows. IB-RS-2 cells were grown in Dulbecco's modified Eagle's medium (DMEM) supplemented with antibiotics, glutamine and 5\% fetal calf serum. Monolayers of IB-RS-2 cells were inoculated with SVDV (SPA/2/'93 isolate (Espuña et al., 1993; Jimenez-Clavero et al., 1998; the nucleotide sequence of the entire P1 capsid coding region is available under GenBank accession No. AY157625) at a multiplicity of infection of approximately 3-5. Virus passes were kept to a minimum (5-6 passes). After incubation at $310 \mathrm{~K}$ for $24 \mathrm{~h}$, when the cytopathic effect was maximum, infection supernatants were collected and clarified by centrifugation at $15000 \mathrm{~g}$ for $20 \mathrm{~min}$. The supernatant containing the virus was inactivated by incubation for $30 \mathrm{~h}$ at $301 \mathrm{~K}$ with $6 \mathrm{mM}$ binary ethylenimine (BEI; Bahnemann, 1975) and then PEG 6000 was added to a final concentration of $8 \%$. This solution was incubated $2-16 \mathrm{~h}$ at $277 \mathrm{~K}$ with shaking and then centrifuged at $15000 \mathrm{~g}$ for $30 \mathrm{~min}$ at $277 \mathrm{~K}$ to allow virus precipitation. The pellet was then resuspended in phosphatebuffered saline (PBS) and clarified by centrifugation at $7700 \mathrm{~g}$ for $20 \mathrm{~min}$ at $277 \mathrm{~K}$. The supernatant was subjected to ultracentrifugation at $130000 \mathrm{~g}$ for $90 \mathrm{~min}$ at $288 \mathrm{~K}$ in order to concentrate the virus. Once resuspended in PBS (approximately $1 / 400$ of the initial volume), the virus concentrate was applied to a 15-35\% sucrose gradient in PBS with $0.5 \%$ sarkosyl and ultracentrifuged at $272000 \mathrm{~g}$ for $1 \mathrm{~h}$ at $283 \mathrm{~K}$. The gradient was fractionated and the virus pooled and quantified by absorbance measurements at 260 and $280 \mathrm{~nm}$. The
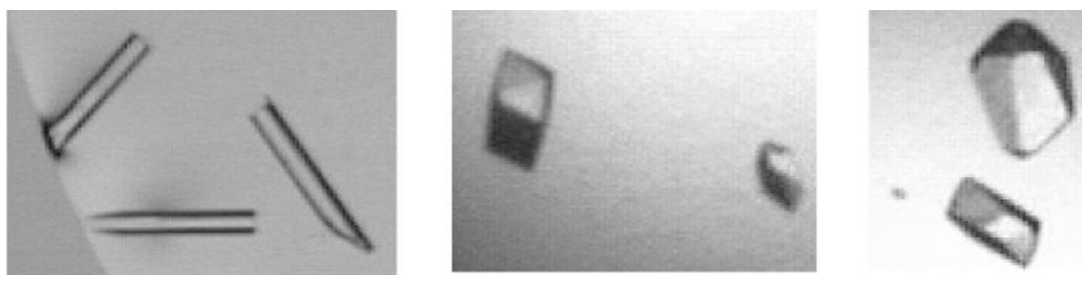

virus was pelleted for a final time by ultracentrifugation $(130000 \mathrm{~g}, 2 \mathrm{~h}, 283 \mathrm{~K})$. The virus was resuspended in distilled water to a final concentration of $5 \mathrm{mg} \mathrm{ml}^{-1}$. Purity of the virus sample was assessed by SDSPAGE stained using Coomassie blue.

\subsection{Crystallization and data collection}

SVDV was crystallized in three different crystal morphologies (Fig. 1) using the hanging-drop vapour-diffusion method. Typically, $2 \mu \mathrm{l}$ of virus solution (5$10 \mathrm{mg} \mathrm{ml}^{-1}$ ) in water were mixed with an equal volume of a reservoir solution.

The first crystal form consists of crystals of parallelepiped shape (Fig. 1a; Table 1) growing to approximately $0.3 \times 0.05 \times$ $0.02 \mathrm{~mm}$ in size, that were obtained using $1.0 \mathrm{M}$ ammonium sulfate and $0.1 \mathrm{M}$ sodium/ potassium phosphate $\mathrm{pH}$ 6.5. These crystals appeared within three to five weeks at $277 \mathrm{~K}$ and diffracted at least to $3.0 \AA$ resolution using synchrotron radiation at ESRF (Grenoble). The unit cell, characterized using $0.3^{\circ}$ rotation diffraction images analyzed with the $D E N Z O$ package (Otwinowski \& Minor, 1997), was consistent with a $C 2$ monoclinic space group with unit-cell parameters $a=473.7, b=385.3, c=472.8 \AA$, $\beta=100.4^{\circ}$. Packing considerations indicated that these monoclinic crystals could contain one virus particle in the asymmetric unit, yielding 60-fold non-crystallographic symmetry (Table 1 ).

A second crystal form, with a cubic morphology (Fig. 1b; Table 1), was obtained at room temperature using $1.5 \mathrm{M}$ ammonium sulfate and $0.1 \mathrm{M}$ sodium/potassium phosphate as precipitants at $\mathrm{pH}$ 6.5. These crystals appeared within a month, reaching dimensions of $0.1 \times 0.1 \times 0.1 \mathrm{~mm}$, and diffracted beyond $2.6 \AA$ resolution using synchrotron radiation (beamline ID14-4 at ESRF, Grenoble). However, our initial attempts to collect data at room temperature were unsuccessful owing to the fact that crystals were stable to the X-ray beam for only one image (exposure time of $20 \mathrm{~s}$ ). In order to extend the diffraction lifetime, the radiation-sensitive crystals were cryo-

\section{Figure 1}

Photomicrographs of the three SVDV crystal forms obtained that diffract to high resolution: (a) monoclinic $C 2$, (b) primitive orthorhombic and (c) body-centred orthorhombic $I 222$.
Table 1

SVDV crystal parameters.

\begin{tabular}{|c|c|c|c|c|}
\hline $\begin{array}{l}\text { Space } \\
\text { group }\end{array}$ & $\begin{array}{l}\text { Reso- } \\
\text { lution } \\
(\AA)\end{array}$ & $\begin{array}{l}\text { Unit-cell } \\
\text { parameters } \\
\left(\AA,{ }^{\circ}\right)\end{array}$ & $\begin{array}{l}\text { Virions } \\
\text { per cell }\end{array}$ & $\begin{array}{l}\text { Packing } \\
\text { density } \dagger \\
\left(\AA^{3} \mathrm{Da}^{-1}\right)\end{array}$ \\
\hline$C 2$ & 3.0 & $\begin{array}{c}a=473.7, \\
b=385.3, \\
c=472.8, \\
\beta=100.4\end{array}$ & 4 & 2.8 \\
\hline$P 2_{x} 2_{x} 2_{x}$ & 2.6 & $\begin{array}{c}a=319.6 \\
b=353.8 \\
c=373.7\end{array}$ & 2 & 2.8 \\
\hline$I 222$ & 3.0 & $\begin{array}{c}a=318.3 \\
b=349.9 \\
c=371.7\end{array}$ & 2 & 2.8 \\
\hline
\end{tabular}

$\dagger$ Calculated assuming a relative mass per virion of $7.5 \times$ $10^{6} \mathrm{Da}$. $\neq$ One of the axes must be a rotation dyad axis (coincident with one of the particle binary axes), while the other two are likely to be $2_{1}$ screw axes.

Table 2

Statistics of data evaluation from the orthorhombic crystal forms.

Values in parentheses are for the highest resolution shell.

\begin{tabular}{lll}
\hline Space group & $I 222$ & $P 2_{x} 2_{x} 2_{x}$ \\
$d_{\min }(\AA)$ & 3.0 & 3.2 \\
No. of crystals used & 2 & 1 \\
No. of images & 115 & 40 \\
Total No. of reflections & 687530 & 442031 \\
No. of independent reflections & 214790 & 200375 \\
Completeness $(\%)$ & $60.0(52.0)$ & $30.5(20.8)$ \\
Average $I / \sigma(I)$ & $4.6(2.8)$ & $3.8(2.0)$ \\
$R_{\text {merge }}^{\dagger}(\%)$ & $16.9(25.0)$ & $19.9(28.1)$ \\
\hline
\end{tabular}

$\dagger R_{\text {merge }}=\sum \sum_{h i}\left|\left\langle I_{h}\right\rangle-I_{h i}\right| / \sum \sum_{h i} I_{h i} \times 100$, where $h$ are unique reflection indices, $I_{h i}$ are intensities of symmetryredundant reflections and $\left\langle I_{h}\right\rangle$ is the mean intensity.

protected by soaking them for $1 \mathrm{~min}$ in a solution containing $30 \%(\mathrm{v} / \mathrm{v})$ glycerol, $1.0 \mathrm{M}$ ammonium sulfate and $0.1 \mathrm{M}$ sodium/ potassium phosphate $\mathrm{pH}$ 6.5. A partial data set to $3.2 \AA$ resolution was collected from one frozen crystal using an ADSC Quantum 4 CCD detector (Table 2). The unit cell was primitive orthorhombic, with unit-cell parameters $a=319.6, b=353.8, c=377.7 \AA$, and contained half a virus particle (30-fold noncrystallographic symmetry) in the asymmetric unit (Table 1).

A third type of crystal, with prismatic morphology and dimensions of up to $0.2 \times$ $0.15 \times 0.1 \mathrm{~mm}$, was also obtained at room temperature and $\mathrm{pH} \quad 6.2$ using $1.2 \mathrm{M}$ ammonium sulfate and $0.1 \mathrm{M}$ sodium/ potassium phosphate (Fig. 1c).

A $3.0 \AA$ data set $(60 \%$ complete $)$ was collected using synchrotron radiation at the ESRF, Grenoble from two crystals cooled to liquid-nitrogen temperature (Fig. 2; Table 2). The cryobuffer was the same as the crystallization buffer but contained $30 \%(v / v)$ glycerol. Diffraction images were evaluated using the DENZO package (Otwinowski \& Minor, 1997). These crystals belong to the orthorhombic space group I222, with unit- 


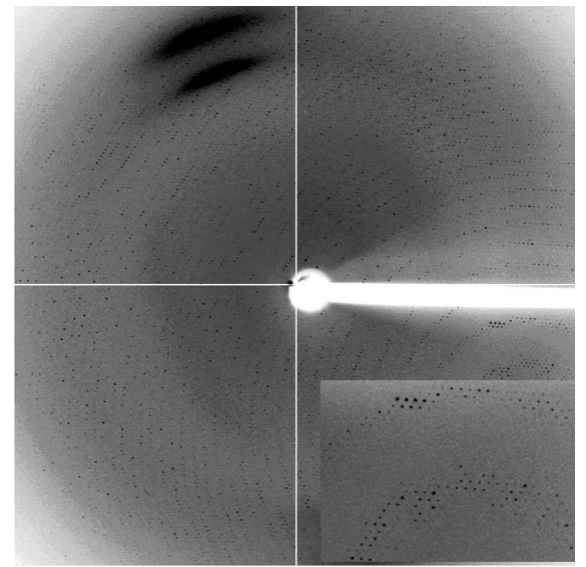

Figure 2

Diffraction photograph of the frozen SVDV crystals. The image corresponds to an $0.3^{\circ}$ oscillation photograph of the orthorhombic 1222 crystals obtained at the ESRF, Grenoble (beamline ID14-4; wavelength 0.939 A) using a Quantum 4 CCD detector. Crystals diffracted to $3.0 \AA$ resolution and were stable to Xray for about 60 images with an exposure time of $20 \mathrm{~s}$ per image. SVDV structure determination and refinement, now in progress, has been carried out using diffraction data from this crystal form.

cell parameters $a=318.3, b=349.9$, $c=371.7 \AA$, and contained two virions per unit cell (15 protomers per asymmetric unit; Table 1) which requires that three perpendicular crystal twofold axes coincide with three of the viral particles dyad axes. Therefore, the centres of the two virus particles in the unit cell are located at positions $(0,0,0)$ and $(1 / 2,1 / 2,1 / 2)$, with particles oriented in one of only two possible orientations, which are related by a $90^{\circ}$ rotation around any of the three orthogonal twofold axes. Structure determination was perfomed by molecular replacement with the programs $X$-PLOR (Brünger, 1992) and $D M$ (Cowtan, 1994), using as a starting model the coordinates of the closely related human coxsackievirus B3 (Muckelbauer et al., 1995) in the two possible orientations. The initially calculated $R$ factors for the two search models gave 50.9 and $38.4 \%$, respectively, for data to $3.5 \AA$ resolution, thus providing an unambiguous discrimination between the two alternative orientations. Structure refinement on this I222 crystal form is now in progress.

\section{Conclusions}

The crystals reported in this work will provide structural information at high resolution for the recent SVDV isolate (SPA/2/ '93). The crystallization and preliminary $\mathrm{X}$-ray analysis of a different SVDV isolate (strain JX/78) has recently been reported (Lin et al., 2002). SVDV-JX/78 crystallizes in a rhombohedral $R 3$ or $R 23$ space group with a long unit-cell axis $(c=1456.1 \AA)$ and diffracts to a maximum resolution of $3.6 \AA$. The determination of both structures will make an accurate comparison of two strains of SVDV possible and therefore make it possible to determine whether any capsid characteristics can be associated with the sequence differences between SVDV strains and with the parental CVB5. In turn, this will provide insights into the evolution of the human CVB5 to infect pigs.

This research was supported by grants BIO099-0865 and BIO2002-00517 from DGICYT to the IBMB and CICYT BIO0980833 to INIA. Data was collected at the EMBL protein crystallography beamlines at ESRF (Grenoble) within a Block Allocation Group (BAG Barcelona). It was financially supported by the ESRF and by grant HPRICT-1999-00022 from the European Union.

\section{References}

Bahnemann, H. G. (1975). Arch. Virol. 47, 47-56. Brocchi, E., Zhang, G., Knowles, N. J., Wilsden, G., McCauley, J. W., Marquardt, O., Ohlinger, V. F. \& De Simone, F. (1997). Epidemiol. Infect. 118, 51-61.

Brünger, A. T. (1992). X-PLOR Version 3.1. A System for X-ray Crystallography and NMR. Yale University, Connecticut, USA.

Cowtan, K. (1994). Jnt CCP4/ESF-EACBM Newsl. Protein Crystallogr. 31, 34-38.

De Castro, M. P. (1964). Arq. Inst. Biol., Sao Paulo, 31, 63-78.

Escribano-Romero, E., Jimenez-Clavero, M. A. \& Ley, V. (2000). Anim. Health Res. Rev. 1, 119 126.

Espuña, E., Alemany, R., Riera, P., Artigas, C., Rosell, R., Pujols, J., Sanmartin, J. \& San Gabriel, A. (1993). Med. Vet. 10, 657-662.

Inoue, T., Yamaguchi, S., Kanno, T., Sugita, S. \& Saeki, T. (1993). Nucleic Acids Res. 21, 38963901.

Jimenez-Clavero, M. A., Escribano-Romero, E., Sanchez-Vizcaino, J. M. \& Ley, V. (1998). Virus Res. 57, 163-170.

Knowles, N. J. \& McCauley, J. W. (1997). Curr. Top. Microbiol. Immunol. 223, 153-167.

Lin, W., Zhao, Q., Bartlam, M., Ding, Y., Li, D., Chen, Y., Bao, H., Xie, Q. \& Rao, Z. (2002). Acta Cryst. D58, 1056-1058.

Muckelbauer, J. K., Kremer, M., Minor, I., Diana, G., Dutko, F. J., Groarke, J., Pevear, D. C. \& Rossmann, M. G. (1995). Structure, 3, 653-667.

Nardelli, L., Lodetti, E., Gualandi, G. L., Burrows, R., Goodridge, D., Brown, F. \& Cartwright, B. (1968). Nature (London), 219, 1275-1276.

Otwinowski, Z. \& Minor, W. (1997). Methods Enzymol. 276, 307-326.

Seechurn, P., Knowles, N. J. \& McCauley, J. W. (1990). Virus Res. 16, 255-274.

Zhang, G., Haydon, D. T., Knowles, N. J. \& McCauley, J. W. (1999). J. Gen. Virol. 80, 639651.

Zhang, G., Wilsden, G., Knowles, N. J. \& McCauley, J. W. (1993). J. Gen. Virol. 74, 845853. 